\title{
Cytoprotective effect of glutaraldehyde erythropoietin on HEK293 kidney cells after silver nanoparticle exposure
}

This article was published in the following Dove Press journal:

International Journal of Nanomedicine

12 February 2016

Number of times this article has been viewed

\author{
Kanidta Sooklert ${ }^{1,2}$ \\ Supreecha Chattong ${ }^{3}$ \\ Krissanapong Manotham ${ }^{3}$ \\ Chawikan Boonwong' \\ I-yanut Klaharn' \\ Depicha Jindatip ${ }^{4}$ \\ Amornpun Sereemaspun ${ }^{1,4}$ \\ 'Nanobiomedicine Laboratory, Department \\ of Anatomy, Faculty of Medicine, \\ ${ }^{2}$ Inter-Department Program of Biomedical \\ Sciences, Faculty of Graduate School, \\ Chulalongkorn University, ${ }^{3}$ Renal Unit, \\ Department of Medicine, Lerdsin General \\ Hospital, ${ }^{4}$ Department of Anatomy, Faculty \\ of Medicine, Chulalongkorn University, \\ Bangkok, Thailand
}

\section{Video abstract}

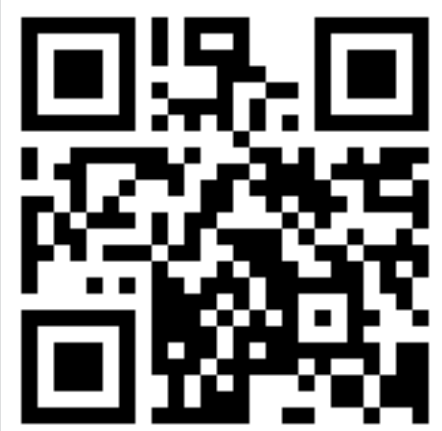

Point your SmartPhone at the code above. If you have a QR code reader the video abstract will appear. Or use

http://youtu.be/hzznwlxKBaU

Correspondence: Amornpun Sereemaspun Nanobiomedicine Laboratory, Department of Anatomy, Faculty of Medicine, Chulalongkorn University, 1873 Rama 4 Road, Pathumwan, Bangkok 10330, Thailand

Tel +66965698859

Fax +66 22527028

Email amornpun.s@chula.ac.th

\begin{abstract}
The toxic effects from exposure to silver nanoparticles (AgNPs), which are broadly present in many consumer products, have long raised concerns. Many studies have focused on the mechanisms of nanosilver, which cause toxicity in human cells, but little is known about prevention of this type of injury. This study investigated the in vitro effects of glutaraldehyde erythropoietin (GEPO), a cytoprotective compound derived from erythropoietin, in terms of cell protection against AgNP-induced injury. HEK293 cells were pretreated with or without GEPO before administration of AgNPs. The protective effects of GEPO in this cell line were assessed by the percentage of viable cells, alterations of cell morphology, and the proliferative capability of the cells. In addition, we assessed the role of GEPO in lowering cellular oxidative stress and regulating expression of the anti-apoptotic protein $\mathrm{Bcl} 2$. The results showed rescue effects on the percentage of viable and proliferative cells among GEPO pretreated cells. Pretreatment with GEPO maintained the normal cell shape and ultrastructural morphology. Moreover, GEPO reduced the generation of reactive oxygen species in cells and activated expression of $\mathrm{Bcl} 2$, which are the major mechanisms in protection against cellular toxicity induced by AgNPs. In conclusion, our study showed that the cytotoxic effects from exposure to AgNPs can be prevented by GEPO.
\end{abstract}

Keywords: glutaraldehyde erythropoietin, silver nanoparticles, cytoprotection, nanotoxicity

\section{Introduction}

Silver nanoparticles (AgNPs) are one of the most widely used nanoparticles in biomedical and industrial fields because of their antimicrobial properties. Various consumer products containing AgNPs have been developed over many decades, such as sterile medical devices, dermatological products, home appliances, surface cleaners, and food storage containers. ${ }^{1,2}$ However, the toxic effects of AgNPs have recently raised concerns. It has been reported that AgNPs can enter the body through many routes of exposure, translocate into the bloodstream, and accumulate in particularly the liver and kidneys. ${ }^{3}$ The kidney is one of the main excretory organs, which removes metabolic wastes, absorbs minerals, and produces hormones. Therefore, aberrations of the kidney can lead to many serious conditions.

Even though AgNP toxicity is well characterized, methods to prevent the toxic effects remain unknown. Previous studies have revealed that AgNPs can induce cellular apoptosis through the mitochondrial-dependent apoptosis pathway that involves downregulation of the pro-survival protein Bcl2. ${ }^{4}$ Many reports show that the main mechanism of AgNP-induced damage in mammalian cells is mediated by increases in the level of intracellular reactive oxygen species (ROS) and oxidative stress. ${ }^{5,6}$ 
Interestingly, this is the same mechanism through which AgNPs induce toxicity in microbes. ${ }^{7}$ Using a general antioxidant to reduce ROS and prevent toxicity also reduces the ability of AgNPs to kill microbes. To optimize AgNPs for killing microbes without toxicity to mammalian cells, a cytoprotective compound is needed to exert antioxidative effects only in mammalian cells.

In this study, we aimed to develop a method to prevent the toxicity of AgNPs for broader and reliable use. Erythropoietin (EPO) and its derivatives have shown benefits in protection of various cells and tissues against acute and chronic injuries. ${ }^{8-12}$ Recently, many researchers have focused on derivatives of EPO because they exert comparative cytoprotective effects with less adverse side effects such as overproduction of red blood cells. ${ }^{13}$ Glutaraldehyde erythropoietin (GEPO), a modified form of EPO, is decidedly one of the most outstanding candidates in terms of protection against cellular injury. This compound was found to exert the same renoprotective effects as EPO both in vitro and in vivo. In addition, GEPO prevents kidney damage by increasing the expression of Bcl2 protein. ${ }^{14}$

The cytoprotective effects of GEPO led to our hypothesis that the cytotoxic activity of AgNPs toward renal cells would be ameliorated by applying this compound. Therefore, this study aimed to evaluate the cytoprotective effects of GEPO on a renal cell line (HEK293) with cytotoxicity induced by AgNPs.

\section{Materials and methods}

\section{Ethics}

Ethics approval was not sought, as the institutional review board of Chulalongkorn University did not require it for the use of human cell lines in this study.

\section{Characterization of AgNPs}

Commercial nanosilver in aqueous buffer, which contained sodium citrate as a stabilizer, was purchased from SigmaAldrich (St Louis, MO, USA). The absorption wavelength of AgNPs was primarily determined using an ultraviolet (UV) spectrophotometer (Beckman Coulter, Brea, CA, USA). To characterize the particle size and shape, an AgNP solution was analyzed in a carbon-coated copper grid by a Hitachi H-7650 transmission electron microscope (TEM) equipped with a charge-coupled device (CCD) camera (Hitachi HighTechnologies Corporation, Tokyo, Japan).

\section{Cell culture}

Human embryonic kidney cells (HEK293) were cultured in Dulbecco's Modified Eagle's Medium (DMEM) supplemented with $10 \%$ fetal bovine serum and $1 \%$ penicillin-streptomycin. The cells were grown in $75 \mathrm{~cm}^{2}$ culture flasks at $37^{\circ} \mathrm{C}$ in a $5 \% \mathrm{CO}_{2}$ incubator.

\section{Cytotoxicity assay}

Because living cells express mitochondrial dehydrogenase, detecting the level of this enzyme was used to assess cell survival. Cell viability assays were conducted in 96-well plates. A total of $5 \times 10^{3}$ cells in $45 \mu \mathrm{L}$ DMEM were seeded into each well and incubated overnight at $37^{\circ} \mathrm{C}$ with $5 \% \mathrm{CO}_{2}$. To determine the dose for induction of cytotoxicity by AgNPs, HEK293 cells were treated with AgNPs at various concentrations (1-100 $\mu \mathrm{g} / \mathrm{mL}$ ) for 4 hours. Prior to AgNPs treatment of HEK293 cells, each dilution of AgNPs was dispersed in DMEM culture media by pipetting. The treatment concentration of AgNPs was determined by the half maximal inhibitory concentration $\left(\mathrm{IC}_{50}\right)$ value. Then, assessment of cytoprotection by GEPO was performed by the following treatments: 1) negative control (DMEM only), 2) AgNPs, 3) GEPO pretreatment before addition of AgNPs, and 4) EPO pretreatment prior to administration of AgNPs. Six replicates were included for each sample. PrestoBlue ${ }^{\mathrm{TM}}$ reagent (Invitrogen, Carlsbad, CA, USA), a cell-permeable compound that becomes highly fluorescent through reduction by dehydrogenase, was then added to each well, followed by incubation for 30 minutes. Cell viability was determined by measurement of the fluorescence intensity using a microplate reader at $530 \mathrm{~nm}$ excitation and $590 \mathrm{~nm}$ emission.

\section{Morphological evaluation}

To analyze changes in cell morphology, HEK293 cells were seeded in 24-well plates at a density of $5 \times 10^{4}$ cells/well and incubated at $37^{\circ} \mathrm{C}$ with $5 \% \mathrm{CO}_{2}$ for 24 hours. Cells cultured in medium alone were used as a negative control. Alterations in cell morphology were assessed in cells treated with $20 \mu \mathrm{g} / \mathrm{mL}$ AgNPs and compared with cells pretreated with $0.42 \mu \mathrm{g} / \mathrm{mL}$ GEPO before addition of AgNPs using a phase contrast microscope (Eclipse TS 100; Nikon, Tokyo, Japan) and TEM (Hitachi).

\section{Death pattern analysis}

The pattern of cell death was determined by flow cytometry (FACSCalibur; Becton Dickinson, Franklin Lakes, NJ, USA) after staining with fluorescein isothiocyanate (FITC)-conjugated annexin $\mathrm{V}$ and propidium iodide (PI) (BD Biosciences, Franklin Lakes, NJ, USA) according to the manufacturer's instructions. Briefly, cells were collected by trypsinization, washed twice with cold phosphate-buffered saline, and resuspended in annexin V binding buffer. FITCconjugated annexin $\mathrm{V}$ and PI working solutions were added to 
the tube containing the collected cells, followed by incubation in the dark at room temperature $\left(25^{\circ} \mathrm{C}\right)$ for 15 minutes. Stained HEK293 cells were analyzed within 1 hour after staining by the FACSCalibur using emission filters for FITC at 530/30 nm and PI at 585/42 $\mathrm{nm}$. The percentage of cells undergoing different types of cell death was analyzed by CellQuest software (Becton Dickinson).

\section{Real-time PCR analysis}

For the cell proliferation assay, $\mathrm{Ki}-67$ gene expression was used to indicate cell cycle progression. Total RNA were isolated from the cells with TRIzol ${ }^{\circledR}$ Reagent (Life Technologies, Carlsbad, CA, USA) and quantified by a micro-volume spectrophotometer at $260 \mathrm{~nm}$. cDNA was synthesized in a $20 \mu \mathrm{L}$ reaction using a RevertAid ${ }^{\mathrm{TM}}$ First Strand cDNA Synthesis Kit (Thermo Scientific, Waltham, MA, USA) according to the manufacturer's instructions. To analyze gene expression in the real-time polymerase chain reaction (PCR) system (StepOnePlus; ABI Applied Biosystems), Express SYBR ${ }^{\circledR}$ GreenER $^{\mathrm{TM}}$ qPCR Supermix Kit was used (Invitrogen). The threshold cycle values for $\mathrm{Ki}-67$ gene amplification were normalized to the endogenous housekeeping gene (GAPDH) expression level in relation to the calibrator.

\section{ROS generation}

To evaluate intracellular ROS levels, we used $2^{\prime}, 7^{\prime}$ dichlorodihydrofluorescein diacetate (DCFH-DA) reagent (Invitrogen). The cells were treated under the same conditions as those for the cell viability assay. HEK293 cells growing in black 96-well plates were treated with DCFH-DA reagent for 30 minutes in the dark. After nonfluorescent DCFH-DA reagent penetrates into cells, esterases within the cells initiate hydrolysis of DCFH-DA to $2^{\prime}, 7^{\prime}$-dichlorodihydrofluorescein. 2', $7^{\prime}$-Dichlorofluorescein produced by oxidation of $2^{\prime}, 7^{\prime}$-dichlorodihydrofluorescein in the presence of ROS was immediately detected using a fluorescence microplate reader at an excitation wavelength of $485 \mathrm{~nm}$ and emission wavelength of $528 \mathrm{~nm}$. The emission intensity of the AgNP-treated group was measured and compared with the GEPO-pretreated group.

\section{Western blotting}

The expression of $\mathrm{Bcl} 2$ protein was examined by Western blot analysis. Cell lysates were centrifuged, and the supernatants were collected. The total protein concentration was determined using a BCA protein assay kit (Thermo Scientific). For immunoblotting, the proteins were loaded onto a $10 \%$ polyacrylamide gel and separated by electrophoresis. Then, the separated proteins were transferred to a polyvinylidene fluoride membrane. The membrane was incubated with a 1:500 dilution of rabbit polyclonal anti$\mathrm{Bcl} 2$ as a primary antibody (Santa Cruz Biotechnology, Santa Cruz, CA, USA) at an optimal overnight at $4^{\circ} \mathrm{C}$. After three washes, the membrane was incubated with a 1:500 dilution of goat anti-rabbit secondary antibody (Santa Cruz Biotechnology) conjugated with horseradish peroxidase for 1 hour. The immunoreactive bands were visualized using an enhanced chemiluminescence Western blot substrate. Equal loading of proteins was confirmed by measuring $\beta$-actin.

\section{Results}

\section{AgNP characteristics}

Commercial AgNPs were characterized by TEM and a UV-vis spectrometer. The particles had a spherical shape and mean size of $10 \mathrm{~nm}$ (Figure 1A). The maximum absorption wavelength was $403 \mathrm{~nm}$ that corresponded to the yellow color of the AgNP dispersion (Figure 1B).
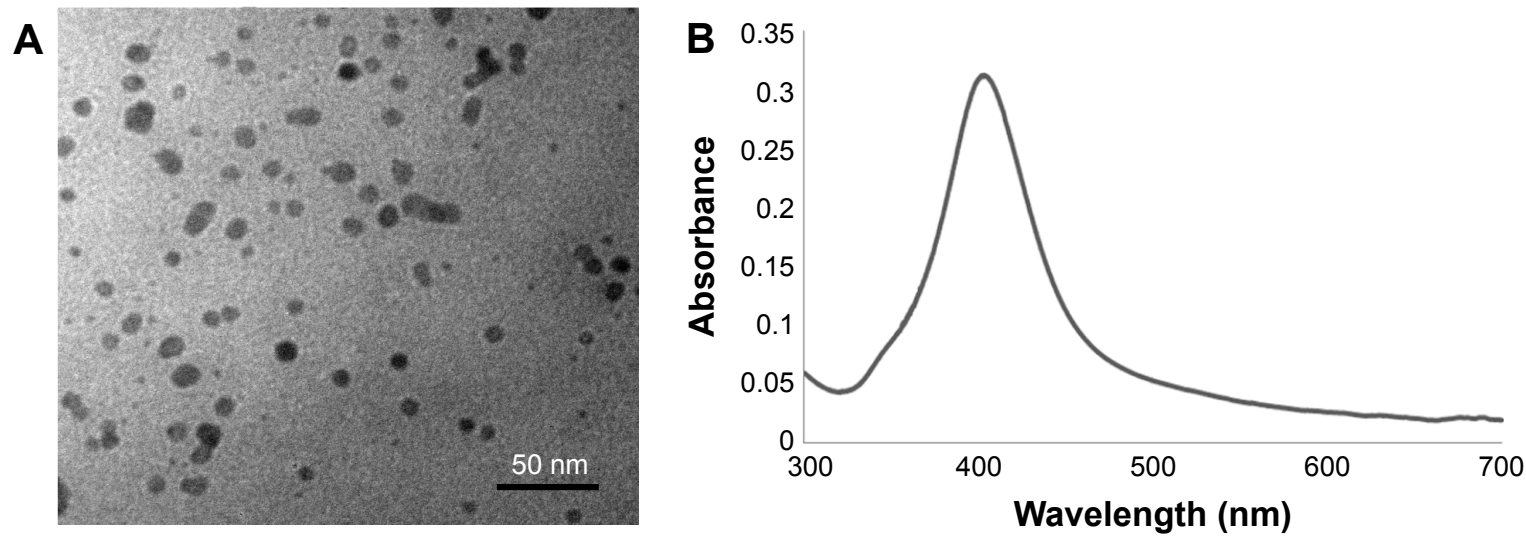

Figure I Characterization of AgNPs by TEM (A) and spectroscopy (B).

Abbreviations: AgNPs, silver nanoparticles; TEM, transmission electron microscopy. 

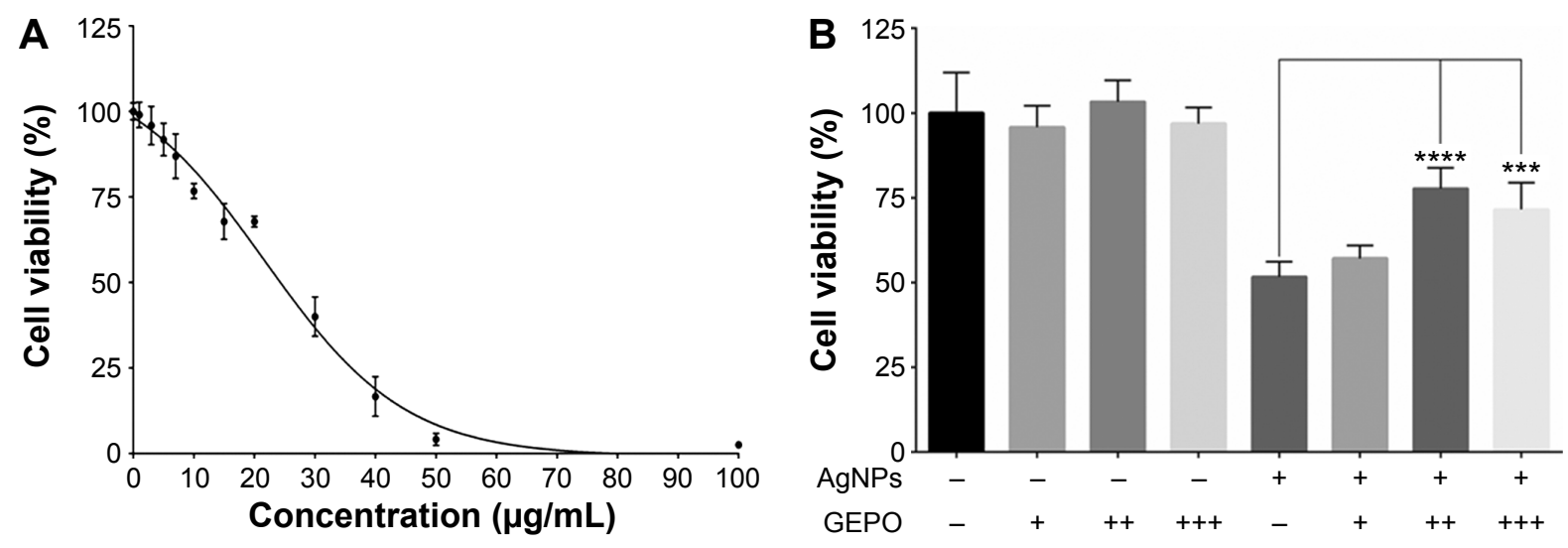

Figure 2 Effect of AgNPs and GEPO on cell viability.

Notes: Effect of AgNPs on the viability of HEK293 cells at 4 hours of exposure (A). Percentage of viable cells following AgNPs exposure with or without GEPO pretreatment (B). Data are the average of four replicate samples (***P $<0.00 \mathrm{I}$ and $* * * * P<0.000 \mathrm{I}$ compared with the AgNP-treated group). + indicates $0.0084 \mu \mathrm{g} / \mathrm{mL} \mathrm{GEPO}$ added; ++ indicates $0.042 \mu \mathrm{g} / \mathrm{mL}$ GEPO added; +++ indicates $0.084 \mu \mathrm{g} / \mathrm{mL}$ GEPO added; and - indicates no GEPO added.

Abbreviations: AgNPs, silver nanoparticles; GEPO, glutaraldehyde erythropoietin.

\section{Cytotoxic effects of AgNPs on HEK293 cells}

The dose-dependent cytotoxic effect of AgNPs on HEK293 cells was examined by a PrestoBlue ${ }^{\mathrm{TM}}$ cell viability assay. HEK293 cells were exposed to AgNPs at concentrations of $1-100 \mu \mathrm{g} / \mathrm{mL}$ for 4 hours. The $\mathrm{IC}_{50}$ was $19.74 \mu \mathrm{g} / \mathrm{mL}$ (Figure 2A). In further experiments, the concentration of $20 \mu \mathrm{g} / \mathrm{mL}$ AgNPs was selected to assess protective effects of GEPO against AgNP-induced cell injury.

\section{GEPO increases cell viability}

We hypothesized that EPO and the derivative GEPO can inhibit the cytotoxicity of AgNPs. Thus, we pretreated HEK293 cells with these compounds and investigated the cell viability after exposure to AgNPs. As a result, the pretreated groups showed significantly higher cell viability than the non-pretreated group (Figure 2B).

\section{GEPO protects against cellular damage}

To determine whether AgNP-induced cytotoxicity was associated with an altered morphology of HEK293 cells, we evaluated the morphological changes of AgNP-exposed cells with and without GEPO pretreatment by phase contrast microscopy and TEM (Figure 3). Compared with the untreated group (Figure 3A and D), AgNP-treated cells showed a distinct morphology and ultrastructural alterations. After incubation with AgNPs, HEK293 cells became round, the number of cells decreased, and the cells detached from
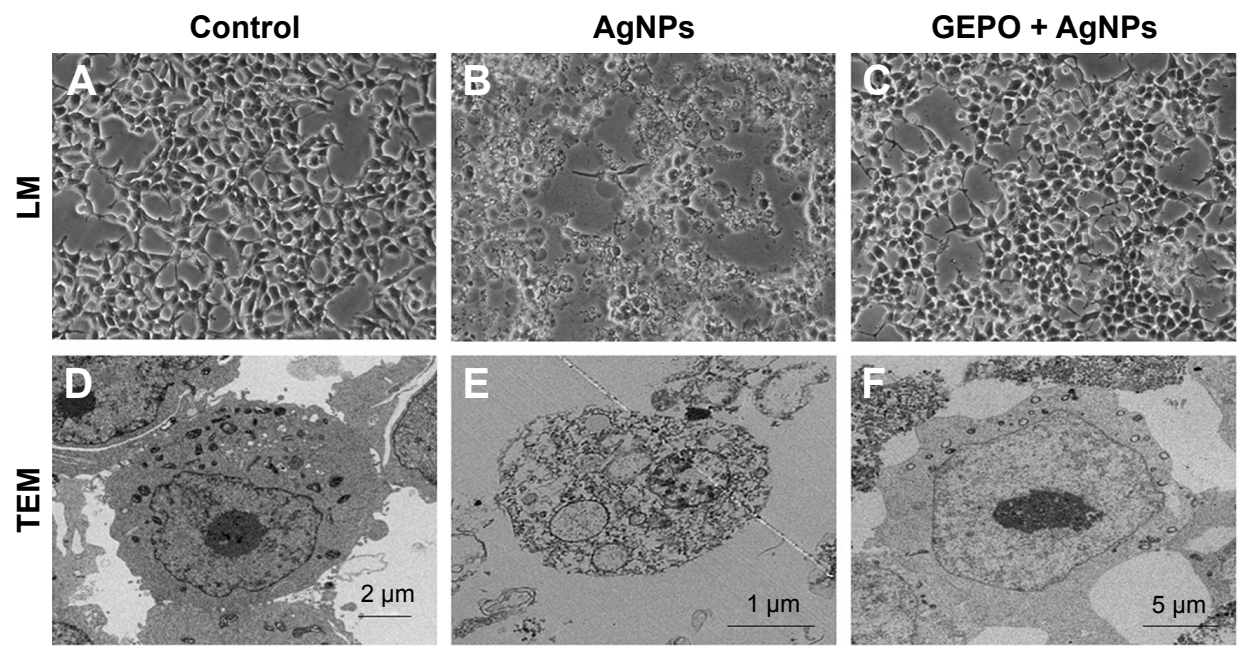

Figure 3 Effect of AgNPs and GEPO on cell morphology.

Notes: Light microscopy and TEM images of untreated cells showed no morphological changes (A and D). After 4 hours of exposure to AgNPs, morphological structures indicating cellular damage and apoptosis were detected (B and E). Pretreatment with GEPO maintained a near normal cell shape (C and $\mathbf{F})$. (A-C) $200 \times$ magnification used. Abbreviations: AgNPs, silver nanoparticles; GEPO, glutaraldehyde erythropoietin; TEM, transmission electron microscopy; LM, light microscopy. 

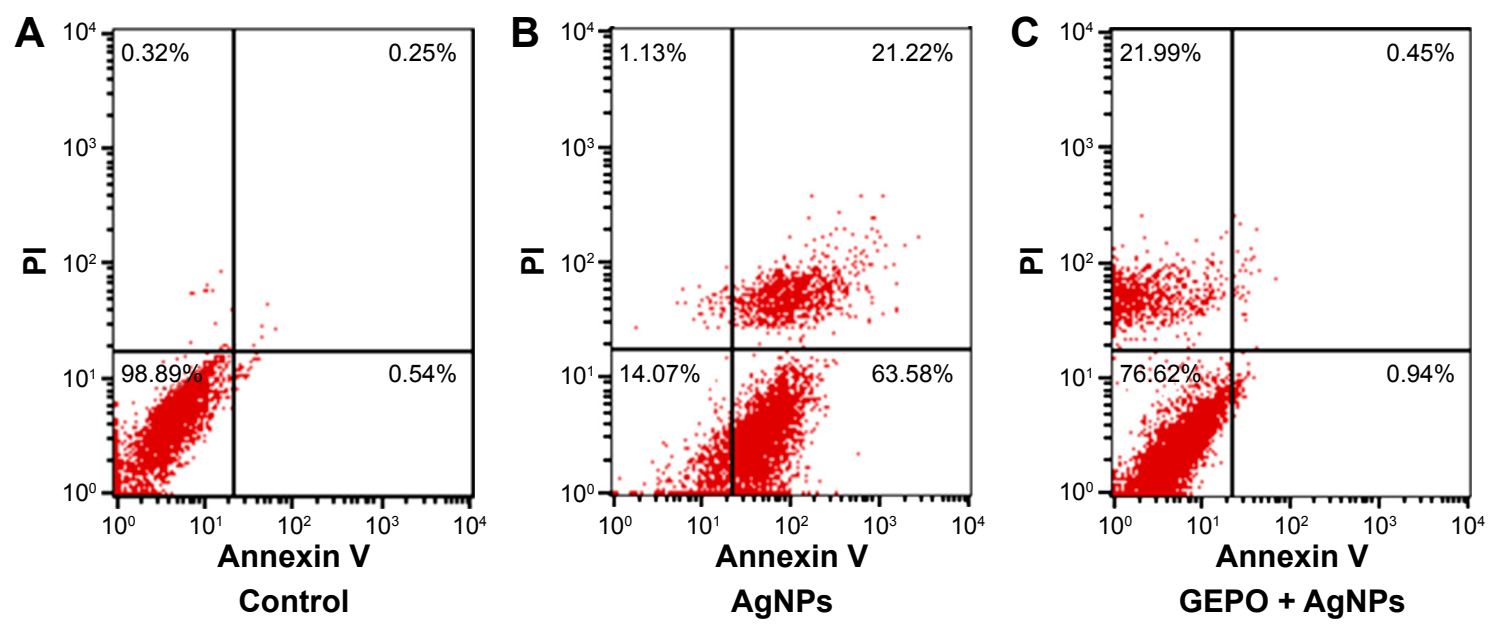

Figure 4 Death pattern analysis of cells treated with DMEM only (A), AgNPs (B), or pretreated with GEPO before administration of AgNPs (C).

Abbreviations: DMEM, Dulbecco's Modified Eagle's Medium; AgNPs, silver nanoparticles; GEPO, glutaraldehyde erythropoietin; PI, propidium iodide.

the surface of the culture plate (Figure 3B). In addition, TEM analysis of AgNP-exposed cells revealed karyolysis and pyknosis characteristics, including nuclear fading due to chromatin dissolution and shrinkage of the nucleus, respectively (Figure 3E). These specific changes in nuclear morphology suggest the initial stage of apoptosis caused by cell damage. On the other hand, GEPO-pretreated cells retained their normal cellular morphological characteristics as shown in both light microscopy and TEM analyses (Figure $3 \mathrm{C}$ and $\mathrm{F}$ ).

\section{Assessment of the cell death pattern}

To confirm the involvement of GEPO in prevention of cell death, both FITC-conjugated annexin V and PI were employed to examine the pattern of cell death. The data showed the percentages of cells that were stained by either annexin V or PI or double-stained by both molecules to indicate cell death or the unstained cells that represent live cells. Cells treated with AgNPs had a higher percentage of apoptotic cells, including early apoptotic cells $(63.58 \%)$ and late apoptotic cells $(21.22 \%)$ compared with GEPO pretreated cells $(0.94 \%$ and $0.45 \%$, respectively) (Figure 4).

\section{GEPO restores the proliferative ability of cells}

To confirm that GEPO maintains the normal proliferation of cells, the expression of Ki-67, which is a marker of cells undergoing proliferation, was evaluated by real-time reverse transcription-PCR (Figure 5). The level of Ki-67 expression in AgNP-exposed cells was unchanged, whereas that in GEPO-pretreated cells before exposure to AgNPs was increased significantly.

\section{GEPO exerts cytoprotective effects via amelioration of ROS}

AgNPs exert toxic effects on cells mainly by increasing ROS generation. To explore the role of GEPO in prevention of ROS production, we next investigated the level of ROS generation. HEK293 cells after treatment with AgNPs showed significant augmentation in the generation of ROS compared with the control group. However, the intracellular ROS, which were generated by AgNP treatment, were substantially attenuated by GEPO pretreatment (Figure 6).

\section{GEPO exerts cytoprotective effects by upregulation of $\mathrm{Bcl} 2$}

In our previous study, we revealed that administration of GEPO induces Bcl 2 expression. ${ }^{14}$ Accordingly, to evaluate

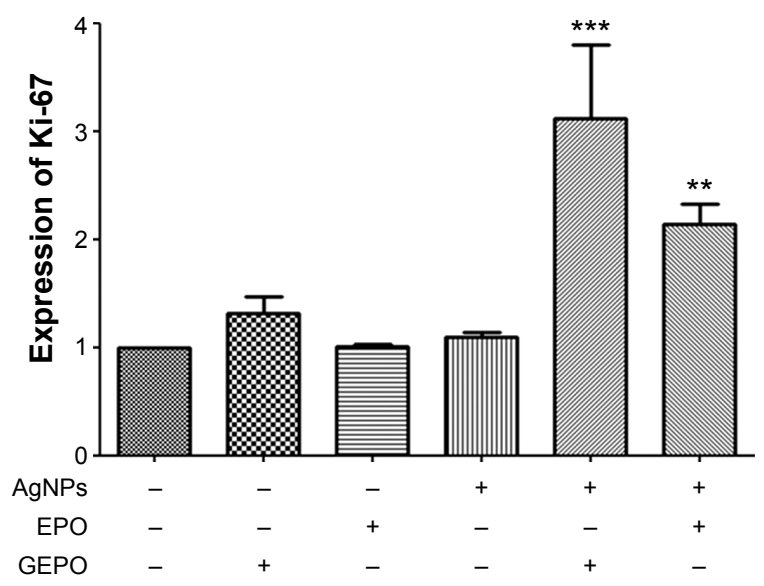

Figure 5 Detection of Ki-67 mRNA expression in HEK293 cells exposed to AgNPs with and without GEPO or EPO pretreatment.

Note: Data are the average of three replicate samples $(* * P<0.001$ and $* * * P<0.000$ I compared with the AgNP-treated group). "-" indicates no GEPO added; "+" indicates $0.042 \mu \mathrm{g} / \mathrm{mL}$ GEPO added.

Abbreviations: AgNPs, silver nanoparticles; GEPO, glutaraldehyde erythropoietin; EPO, erythropoietin. 


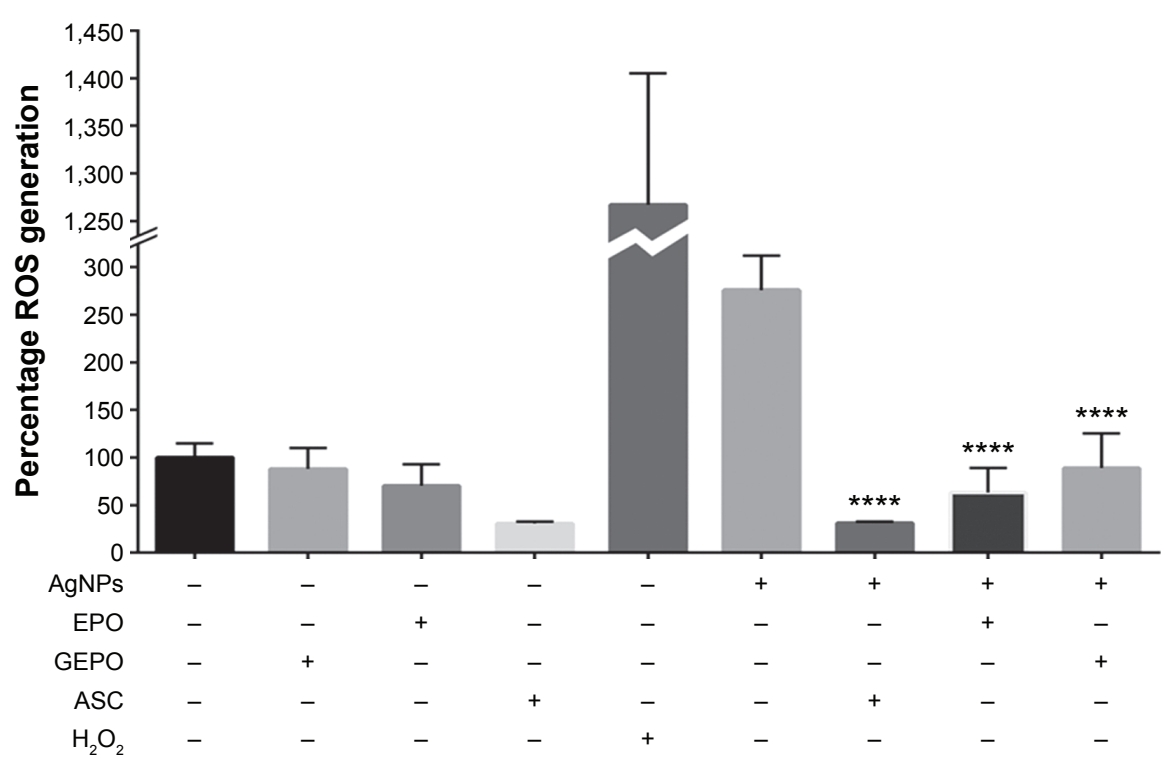

Figure 6 ROS generation of HEK293 cells in the presence of AgNPs with and without GEPO or EPO pretreatment.

Note: Data are the average of four replicate samples (**** $P<0.000$ I compared with the AgNP-treated group).

Abbreviations: ROS, reactive oxygen species; AgNPs, silver nanoparticles; GEPO, glutaraldehyde erythropoietin; EPO, erythropoietin; ASC, ascorbic acid.

the effect of GEPO on AgNP-exposed cells, Western blot analysis was applied to measure Bcl2 protein expression. We found that AgNPs considerably inhibited the expression of Bcl2 protein, whereas cells pretreated with GEPO showed upregulation of $\mathrm{Bcl} 2$ protein expression (Figure 7).

\section{Discussion}

In this study, we investigated the effect of GEPO, a cytoprotective compound that has been shown to protect against renal cell apoptosis by upregulation of $\mathrm{Bcl} 2$ protein as well as ameliorate kidney damage induced by ischemic/ reperfusion conditions. ${ }^{14}$ Our results revealed that AgNPexposed cells had morphological damage, decreased cell viability, increased ROS generation, and downregulated Bcl2 expression. Pretreatment with GEPO not only attenuated the ROS production but also upregulated $\mathrm{Bcl} 2$ expression, which probably contributed to rescuing the cellular damage induced by AgNPs. Therefore, GEPO possibly has a beneficial effect on AgNP-induced renal cell injury.

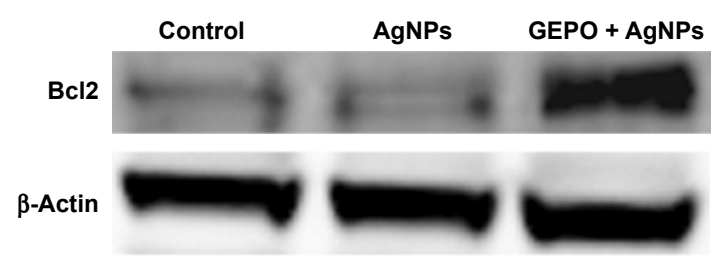

Figure 7 Western blot analysis of $\mathrm{Bcl} 2$ protein in AgNP-treated cells with or without GEPO pretreatment.

Abbreviations: AgNP, silver nanoparticle; GEPO, glutaraldehyde erythropoietin.
AgNPs are one of the most popular nanomaterials in many consumer products. The expansion in the use of nanosilver has led to an increase in the awareness of its toxicity. ${ }^{15,16}$ AgNPs damage cells, which contributes to the generation of free radicals and the consequential cellular oxidative stress and reduction in $\mathrm{Bcl} 2$ protein expression. ${ }^{15} \mathrm{Bcl} 2$ protein has a role in the antioxidant pathway and has been reported to protect cells against apoptosis induced by ROS. ${ }^{17,18}$ Thus, an approach that possibly targets both the cellular stresses resulting from ROS generation and regulation of $\mathrm{Bcl} 2$ protein expression is an appropriate strategy for the prevention and treatment of cellular injury caused by AgNPs.

Although it is unclear how GEPO prevents AgNPinduced cellular injury, our previous study showed that GEPO has a binding affinity for a tissue-protective receptor, the IL3RB/EPOR heterotrimeric receptor. ${ }^{14}$ Under normal conditions, this tissue-protective receptor is not expressed but appears when cells are exposed to noxious stimuli. ${ }^{19}$ Tissue-protective compounds including modified forms of recombinant human EPO have been reported to exert protective effects via this receptor. ${ }^{13,19,20}$ The initial step after these types of tissue-protective molecules bind to the IL3RB/EPOR heterotrimeric receptor is autophosphorylation of the JAK2 molecule. Following JAK2 phosphorylation, STAT, PI3K/Akt, and MAPK pathways are activated. The activation of these three pathways plays an important role in the regulation of mitochondrial integrity, activation of anti-apoptotic signals, and inhibition of pro-apoptotic 
molecules. ${ }^{19}$ Therefore, it is possible that the cytoprotective effects of GEPO are mediated by activation of the IL3RB/ EPOR heterotrimeric receptor.

The prominent features of cells after exposure to AgNPs are cytotoxicity, including a reduction in cell viability, abnormal morphology, and an impairment in the ability to proliferate. ${ }^{21-23}$ Previous reports have suggested that exposure to AgNPs causes cell cycle arrest. ${ }^{24,25}$ Conversely, based on our results, AgNPs had no significant effect on cell proliferation compared with the control. Ahamed et al found that the toxic effects of AgNPs are not only dependent on cell type-specific responses to this nanomaterial but also related to concentration-dependent effects. ${ }^{26}$ A low dose of AgNPs has anti-proliferative effects, whereas a high dose has been shown to activate cell proliferation. ${ }^{27}$ These findings suggest that a toxic concentration of AgNPs may function as a molecular activator of proliferative pathways.

In our study, treatment of the renal cell line with GEPO promoted the cells to enter the active phase of the cell cycle. Interestingly, the level of proliferation observed in cells pretreated with GEPO and then treated with AgNPs was higher than that in cells treated with GEPO alone. It is likely that either both GEPO and AgNPs have the potential to increase cell proliferation independently or AgNPs might play a role in amplifying the proliferative effect of GEPO in the deleterious environments induced by AgNPs. A possible explanation for the combined effect of AgNPs and GEPO in the augmentation of renal cell proliferation is cross-regulation of the JNK pathway by these two molecules. JNK is a member of the MAPK family and functions as a key molecular mediator in the activation of cell proliferation. ${ }^{28,29}$ Activation of the JNK pathway has been reported to be triggered by cellular oxidative stress resulting from AgNPs and functions as a regulator in the activation of compensatory cell proliferation. ${ }^{30-33}$ Moreover, EPO has been found to potentially stimulate this pathway and consequently induce cell proliferation. ${ }^{34,35}$

We found an increase in the number of apoptotic cells among cells treated with AgNPs alone, whereas pretreatment with GEPO decreased the percentage of apoptotic cells. However, the pattern of cell death among cells pretreated with GEPO appeared to switch from apoptosis to necrosis. Previous studies have reported that EPO and its derivative exert protective effects by inhibiting caspase- 9 and -3 activities. ${ }^{20,36}$ In addition, it has been revealed that the mechanism underlying the switch in the pattern of cell death is related to inhibition of caspases. ${ }^{37,38}$ Based on these findings, we propose that GEPO reduces cell death not only by increasing expression of the anti-apoptotic protein $\mathrm{Bcl} 2$ but also by inhibition of caspases involved in apoptosis.

In addition to the protection of renal cells, based on our results, GEPO was found to exert antioxidative effects. Pretreatment with GEPO before AgNP treatment diminished the induced ROS generation, one of the major causes of AgNP-induced cellular injury. ${ }^{5,22}$ This is the first report to show that GEPO prevents ROS generation. We propose the possibility that GEPO acts in a similar manner as EPO. Previous studies have reported direct antioxidative effects of EPO in renal endothelial cells. ${ }^{39,40}$ In addition, EPO increases antioxidative enzyme expression as well as upregulates $\mathrm{Nrf} 2$ and heme oxygenase-1. ${ }^{39-42}$ Upregulation of Nrf2 and heme oxygenase-1 has significant protective effects against AgNPinduced cellular toxicity. ${ }^{43,44}$

The present study demonstrated the ability to prevent AgNP-induced cell injury by GEPO, which decreased ROS generation and stimulated $\mathrm{Bcl} 2$ expression. These findings increase our understanding of GEPO as a cellular protective compound and suggest a molecular mechanism of this agent. However, the mechanisms of action of GEPO in the reduction of ROS and activation of $\mathrm{Bcl} 2$ protein expression are still unknown. Further studies are needed to reveal the precise mechanism and the associated pathways of GEPO in protection against cellular toxicity induced by AgNPs.

\section{Conclusion}

In summary, our data confirmed that, under conditions of cellular oxidative stress and the consequential cytotoxicity induced by AgNPs, GEPO exhibited a cytoprotective function in the renal cell model. GEPO is able to reduce ROS generation and promote expression of the pro-survival protein Bcl2, which promoted cell survival. This finding sheds light on prevention of nanosilver toxicity. The next step is to better understand the cell signaling processes that are specifically responsible for cell protection conferred by GEPO. Based on this knowledge, AgNPs can be potentially used without cellular toxicity, at least in human kidney cells.

\section{Acknowledgments}

The authors gratefully acknowledge Professor Suwabun Chirachanchai from The Petroleum and Petrochemical College, Chulalongkorn University for critical comments on this paper. This research has been supported by the Ratchadaphiseksomphot Endowment Fund of Chulalongkorn University (CU-56-431-HR) for all biological experiments in this study, and partially supported by the Integrated Innovation Academic Center: IIAC Fund from the Chulalongkorn 
University Centenary Academic Development Project for the glutaraldehyde erythropoietin synthesis and characterization aspect of this study.

\section{Disclosure}

AS was supported by the Research Chair Grant, National Science and Technology Development Agency (NSTDA), Thailand and supported in part by "Integrated Innovation Academic Center: IIAC" Chulalongkorn University Centenary Academic Development Project. KS was supported by the 90th Anniversary of Chulalongkorn University Fund (Ratchadaphiseksomphot Endowment Fund). SC was supported by postdoctoral scholarship from Chulalongkorn University. The authors report no other conflicts of interest in this work.

\section{References}

1. Ge L, Li Q, Wang M, Ouyang J, Li X, Xing MM. Nanosilver particles in medical applications: synthesis, performance, and toxicity. Int J Nanomed. 2014;9:2399-2407.

2. Wijnhoven SW, Peijnenburg WJ, Herberts CA, et al. Nano-silver-a review of available data and knowledge gaps in human and environmental risk assessment. Nanotoxicology. 2009;3(2):109-138.

3. Tang J, Xiong L, Wang S, et al. Distribution, translocation and accumulation of silver nanoparticles in rats. J Nanosci Nanotechnol. 2009; 9(8):4924-4932.

4. Foldbjerg R, Autrup H. Mechanisms of silver nanoparticle toxicity. Arch Basic Appl Med. 2013;1(1):5-15.

5. Bartłomiejczyk T, Lankoff A, Kruszewski M, Szumiel I. Silver nanoparticles-allies or adversaries. Ann Agric Environ Med. 2013;20(1): 48-54.

6. Patlolla AK, Hackett D, Tchounwou PB. Genotoxicity study of silver nanoparticles in bone marrow cells of Sprague-Dawley rats. Food Chem Toxicol. 2015;85:52-60. doi:10.1016/j.fct.2015.05.005.

7. Pelgrift RY, Friedman AJ. Nanotechnology as a therapeutic tool to combat microbial resistance. Adv Drug Deliv Rev. 2013;65(13-14): 1803-1815.

8. Liu X, Zhu B, Zou H, et al. Carbamylated erythropoietin mediates retinal neuroprotection in streptozotocin-induced early-stage diabetic rats. Graefes Arch Clin Exp Ophthalmol. 2015;253(8):1263-1272.

9. Mofidi A, Bader A, Pavlica S. The use of erythropoietin and its derivatives to treat spinal cord injury. Mini Rev Med Chem. 2011;11(9): $763-770$.

10. Nguyen AQ, Cherry BH, Scott GF, Ryou MG, Mallet RT. Erythropoietin: powerful protection of ischemic and post-ischemic brain. Exp Biol Med (Maywood). 2014;239(11):1461-1475.

11. Wang Y, Lu X, He J, Zhao W. Influence of erythropoietin on microvesicles derived from mesenchymal stem cells protecting renal function of chronic kidney disease. Stem Cell Res Ther. 2015;6(1):100.

12. Sanchis-Gomar F, Garcia-Gimenez JL, Pareja-Galeano H, Romagnoli M, Perez-Quilis C, Lippi G. Erythropoietin and the heart: physiological effects and the therapeutic perspective. Int J Cardiol. 2014; 171(2):116-125.

13. Van Rijt WG, Van Goor H, Ploeg RJ, Leuvenink HG. Erythropoietinmediated protection in kidney transplantation: nonerythropoietic EPO derivatives improve function without increasing risk of cardiovascular events. Transpl Int. 2014;27(3):241-248.

14. Chattong S, Tanamai J, Kiatsomchai P, et al. Glutaraldehyde erythropoietin protects kidney in ischaemia/reperfusion injury without increasing red blood cell production. Br J Pharmacol. 2013;168(1): 189-199.
15. Dubey P, Matai I, Kumar SU, Sachdev A, Bhushan B, Gopinath P. Perturbation of cellular mechanistic system by silver nanoparticle toxicity: cytotoxic, genotoxic and epigenetic potentials. Adv Colloid Interface Sci. 2015;221:4-21.

16. Gaillet S, Rouanet JM. Silver nanoparticles: their potential toxic effects after oral exposure and underlying mechanisms - a review. Food Chem Toxicol. 2015;77:58-63.

17. Hockenbery DM, Oltvai ZN, Yin XM, Milliman CL, Korsmeyer SJ. Bcl-2 functions in an antioxidant pathway to prevent apoptosis. Cell. 1993;75(2):241-251.

18. Hildeman DA, Mitchell T, Aronow B, Wojciechowski S, Kappler J, Marrack P. Control of Bcl-2 expression by reactive oxygen species. Proc Natl Acad Sci U S A. 2003;100(25):15035-15040.

19. Brines M, Cerami A. The receptor that tames the innate immune response. Mol Med. 2012;18:486-496.

20. Yang C, Zhao T, Lin M, et al. Helix B surface peptide administered after insult of ischemia reperfusion improved renal function, structure and apoptosis through beta common receptor/erythropoietin receptor and PI3K/Akt pathway in a murine model. Exp Biol Med (Maywood). 2013; 238(1):111-119.

21. Brzoska K, Meczynska-Wielgosz S, Stepkowski TM, Kruszewski M. Adaptation of HepG2 cells to silver nanoparticles-induced stress is based on the pro-proliferative and anti-apoptotic changes in gene expression. Mutagenesis. 2015;30(3):431-439.

22. Kruszewski M, Brzoska K, Brunborg G, et al. Toxicity of silver nanomaterials in higher eukaryotes. Adv Mol Toxicol. 2011;5:179-218.

23. Bhakat C, Chetal G, Sarkar P, Singh P, Babu S, Reddy A. Effects of silver nanoparticles synthesize from ficus benjamina on normal cells and cancer cells. IOSR J Pharm Biol Sci. 2012;1:33-36.

24. Kang SJ, Lee YJ, Lee EK, Kwak MK. Silver nanoparticles-mediated $\mathrm{G} 2 / \mathrm{M}$ cycle arrest of renal epithelial cells is associated with NRF2-GSH signaling. Toxicol Lett. 2012;211(3):334-341.

25. Lee YS, Kim DW, Lee YH, et al. Silver nanoparticles induce apoptosis and G2/M arrest via PKCzeta-dependent signaling in A549 lung cells. Arch Toxicol. 2011;85(12):1529-1540.

26. Ahamed M, Alsalhi MS, Siddiqui MK. Silver nanoparticle applications and human health. Clin Chim Acta. 2010;411(23-24):1841-1848.

27. Rosas-Hernandez H, Jimenez-Badillo S, Martinez-Cuevas PP, et al. Effects of 45-nm silver nanoparticles on coronary endothelial cells and isolated rat aortic rings. Toxicol Lett. 2009;191(2-3):305-313.

28. Hui L, Bakiri L, Mairhorfer A, et al. p38alpha suppresses normal and cancer cell proliferation by antagonizing the JNK-c-Jun pathway. Nature. 2007;39(6):741-749.

29. Sabapathy K, Hochedlinger K, Nam SY, Bauer A, Karin M, Wagner EF. Distinct roles for JNK1 and JNK2 in regulating JNK activity and c-Jundependent cell proliferation. Mol Cell. 2004;15(5):713-725.

30. Hsin Y-H, Chen C-F, Huang S, Shih T-S, Lai P-S, Chueh PJ. The apoptotic effect of nanosilver is mediated by a ROS-and JNK-dependent mechanism involving the mitochondrial pathway in NIH3T3 cells. Toxicol Lett. 2008;179(3):130-139.

31. Satapathy SR, Mohapatra P, Das D, Siddharth S, Kundu CN. The apoptotic effect of plant based nanosilver in colon cancer cells is a p53 dependent process involving ROS and JNK cascade. Pathol Oncol Res. 2015;21(2):405-411.

32. Fan Y, Bergmann A. Apoptosis-induced compensatory proliferation. The Cell is dead. Long live the Cell!. Trends Cell Biol. 2008;18(10): 467-473.

33. Ryoo HD, Gorenc T, Steller H. Apoptotic cells can induce compensatory cell proliferation through the JNK and the wingless signaling pathways. Dev Cell. 2004;7(4):491-501.

34. Jacobs-Helber SM, Ryan JJ, Sawyer ST. JNK and p38 are activated by erythropoietin (EPO) but are not induced in apoptosis following EPO withdrawal in EPO-dependent HCD57 cells. Blood. 2000;96(3): 933-940.

35. Jacobs-Helber SM, Sawyer ST. Jun N-terminal kinase promotes proliferation of immature erythroid cells and erythropoietin-dependent cell lines. Blood. 2004;104(3):696-703. 
36. Chong ZZ, Kang JQ, Maiese K. Apaf-1, Bcl-xL, cytochrome c, and caspase- 9 form the critical elements for cerebral vascular protection by erythropoietin. J Cereb Blood Flow Metab. 2003;23(3):320-330.

37. Nikoletopoulou V, Markaki M, Palikaras K, Tavernarakis N. Crosstalk between apoptosis, necrosis and autophagy. Biochim Biophys Acta. 2013;1833(12):3448-3459.

38. Lemaire C, Andréau K, Souvannavong V, Adam A. Inhibition of caspase activity induces a switch from apoptosis to necrosis. FEBS Lett. 1998;425(2):266-270.

39. Katavetin P, Tungsanga K, Eiam-Ong S, Nangaku M. Antioxidative effects of erythropoietin. Kidney Int. 2007;72:S10-S15.

40. Katavetin P, Inagi R, Miyata T, et al. Erythropoietin induces heme oxygenase-1 expression and attenuates oxidative stress. Biochem Biophys Res Commun. 2007;359(4):928-934.
41. Jin W, Kong J, Lu T, et al. Erythropoietin prevents secondary brain injury induced by cortical lesion in mice: possible involvement of $\mathrm{Nrf} 2$ signaling pathway. Ann Clin Lab Sci. 2011;41(1):25-32.

42. Genc K, Egrilmez MY, Genc S. Erythropoietin induces nuclear translocation of Nrf2 and heme oxygenase-1 expression in SH-SY5Y cells. Cell Biochem Funct. 2010;28(3):197-201.

43. Piao MJ, Kim KC, Choi J-Y, Choi J, Hyun JW. Silver nanoparticles down-regulate Nrf2-mediated 8-oxoguanine DNA glycosylase 1 through inactivation of extracellular regulated kinase and protein kinase B in human Chang liver cells. Toxicol Lett. 2011;207(2):143-148.

44. Kang SJ, Ryoo I-g, Lee YJ, Kwak M-K. Role of the Nrf2-heme oxygenase-1 pathway in silver nanoparticle-mediated cytotoxicity. Toxicol Appl Pharmacol. 2012;258(1):89-98.
International Journal of Nanomedicine

\section{Publish your work in this journal}

The International Journal of Nanomedicine is an international, peerreviewed journal focusing on the application of nanotechnology in diagnostics, therapeutics, and drug delivery systems throughout the biomedical field. This journal is indexed on PubMed Central, MedLine, CAS, SciSearch ${ }^{\circledR}$, Current Contents ${ } /$ Clinical Medicine,

\section{Dovepress}

Journal Citation Reports/Science Edition, EMBase, Scopus and the Elsevier Bibliographic databases. The manuscript management system is completely online and includes a very quick and fair peer-review system, which is all easy to use. Visit http://www.dovepress.com/ testimonials.php to read real quotes from published authors.

Submit your manuscript here: http://www.dovepress.com/international-journal-of-nanomedicine-journal 